\title{
The evaluation of library services: a concise review of the existing literature
}

Dr. F.W. Lancaster

Profesor Emeritus University of Illinois at Urbana-Champaign 501 East Daniel Street Champaign, Il 61820-6212 fax 9521724433020

\begin{abstract}
RESUMEN
Se presenta una reseña bibliográfica de los estudios más sobresalientes sobre evaluación de los servicios bibliotecarios, en donde se señala su origen y desarrollo a partir de la década del 60. En forma cronológica, se comentan aquellos aportes estimados por el autor como clásicos o más significativos en lo referente a los aspectos considerados en la evaluación de los servicios bibliotecarios; algunos de las cuales son los relativos ala evaluación de colecciones, evaluación del servicio de referencia, análisis costo-eficiencia y costo-beneficio, así como otros incorporados recientemente, entre los que destacan el rango y alcance de los servicios, la cooperación de recursos y los estudios sobre la satisfacción de las necesidades de información de los usuarios. Se incluye una bibliografía selectiva sobre el tema..
\end{abstract}

\begin{abstract}
$\boldsymbol{A}$ bibliographical review of the most outstanding studies regarding the assessment of library services, establishing their origin and development since the decade of the sixties. Chronologically, the contributors which the author considers to be classics, or more significant regarding the features included in the assessment of library services, some of which address the assessment, as well as other features recently included, among which emphasis is made on the range and scope of the services, operation of resources and studies concerning the fulfillment of the information needs of the users. A select bibliography pertaining to these matters is included.
\end{abstract}

\section{INTRODUCTION}

$\boldsymbol{W}$ hile a few isolated and limited attempts occurred earlier, the application of significant objective approaches to the evaluation of library services was virtually unknown before the 1960. The first serious attempt to develop objective evaluation procedures emerged in studies performed for the National Library of Medicine by Orr et al. (1968). Somewhat later, Orr (1973) prepared a "classic" paper on the importance of evaluation procedures for library managers.

The next milestone was the manual of performance measures for public libraries prepare by DeProspo et al. (1973), which significantly influenced the later manuals published by the American Library Association for the evaluation of public libraries (Van House et al., 1987) and of academic libraries (Van House et al., 1990).

Since the 1960, many hundreds of evaluative studies have been performed in libraries and the literature has become very extensive. Comprehensive reviews exist in books by Ba- ker and Lancaster (1991) and Lancaster (1993).

This report is note intended as another comprehensive discussion of library-related evaluation procedures but, rather, a highly selective review of the relevant literature. The purpose is to identify major approaches to the evaluation of various facets of library service and to point to the literature that this author feels to be of most value or importance. Therefore, it should serve as useful guide for librarians in Mexico who are contemplating the evaluation of some aspect of their services by suggesting possible approaches and by referring to the most significant examples, discussions or critiques of these approaches.

\section{COLLECTION- RELATED EVALUATION}

Three major approaches to the evaluation of library collections can be identified:
1) Comparing parts of the collection against bibliographies of various types.

2) Comparing strengths of the collection in carious subjects areas with measures of community interest (e.g., student enrollment in courses).

3) Analyzing circulation records in an attempt to determine, from amount of use, whether or not present collection development policies seem appropriate.

Special aspects of collection evaluation include studies of in-house use, the evaluation of periodicals, the weeding of collections, studies of space utilization, and materials availability studies. Each of these will be discussed in turn.

\section{Bibliographic checking}

This approach (sometimes referred to as "list checking"), which is most appropriate for academic or other research libraries, involves comparing a particular subject area of the collection with a bibliography of items that are 
supposed to be important items in that area. For most subject fields, no standard list of "best" literature will exist. Therefore, the librarian who wants to apply this approach must compile a list for evaluation purposes.

The most obvious sources to draw upon are the lists of materials cited by scholars writing recently in the field -in monographs, journal articles or other publication forms. The underlying assumption is that the sources cited are those needed by the scholars to support their research and that these sources should appear in a strong collection in this subject area. When a librarian applies such a list to evaluate his own collection in this subject field, he is really asking the question "Could this research have been supported here?"

The classic study of this kind was performed by Coale (1965), using sources cited in scholarly monographs. Lopez (1983) proposed a similar approach, which would actually give a numerical score to reflect the strength of the collection in this subject, but this method is unnecessarily complicated and cannot really be recommended. Others have drawn references form the bibliographies of scholarly journal articles, from dissertations, or other publication forms. Nisonger (1992) has prepared a useful survey of this and other approaches to collection evaluation. The advantages and disadvantages of using different types of publications as sources for bibliographic checking are discussed in detail in Chapter 2 of Lancaster (1993).

A related and potentially valuable approach, although it has been little used, is to tale the references retrieved in database searches as a set of items appropriate to evaluate the collection of the library in which the searches were performed. The justification is obvious; the subjects of the searches reflect the interests of at least some library users and the items retrieved should be the ones that these users will be looking for in the library. A rare example of this approach, which seems particularly appropriate to the evaluation of special libraries can be found in Lancaster et al. (1991c).

\section{Collection analysis}

Automated systems of various kinds in libraries can act as management information systems — giving the library manager better data on which to base decisions or establish policies. A systematic analysis of the present collection can in itself be a useful evaluative procedure, indicating subject areas in which the collection appears unusually strong and areas in which it appears weaker. Detailed collection analyses were difficult to perform in the pre-automation era but should be simple when a library has detailed automated records

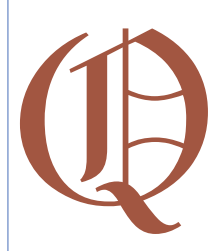

for all items owned. Kountz (1991) provides an excellent example of an analysis of this type. In a large university environment, he was able to compare the strength of student interests as reflected in number of the collection in various courses. The underlying assumption is that, if student enrollment in a particular subject area (say bacteriology) is strong but the library buys few books in this field, this may indicate a defect in the collection development policy, as would a case in which the library buys a lot in an area of little student interest.

\section{Circulation analysis}

Automated circulation systems can provide data that are of great value in collection evaluation. Clearly, circulation figures reflect an important use of collection. When these figures are broken down by classification number, the strength of user interest in various subject areas is revealed.

valuable approach, although it
has been little used, is to tale
the references retrieved in
database searches as a set of
items appropriate to evaluate
the collection of the library in
which the searches were
performed.

Circulation data are of most value when they are related to data on the holdings of the library in various subject areas. There are several ways in which circulation data can be related to holdings data. One measure is turnover rate (Van House, et al., 1987), which is the average number of times that a book in a particular subject field is borrowed in a year, each book is borrowed once a year on average and the turnover rate is 1.0. If circulation was doubled, turnover would be 2.0. Classes with very low turnover relative to the other classes are those in which user interest is very low. At least, users are not very interested in the books the library now owns on these subjects. The librarian should closely examine these classes to see what corrective action is needed (e.g., weed out obsolete material from the collection, buy fewer books in this subject in the future, or buy different books in this area).

A second way of comparing holdings with the circulation is by counts of the proportion of the collection in various subject areas that is absent from the shelves (in circulation) at a particular time. Consider two subject classes, $x$ and $y$, with exactly 500 books in each. Today there are $400 x$ books in circulation and only 100 on the shelves. For class y the situation is reversed: 400 books on the shelf and 100 in circulation. Clearly, $x$ is a heavily used class and $y$ is not. Relative to the other classes in the library, $x$ may be one of several heavily overused classes while $y$ may be one of several that are heavily underused. Classes at both extremes of the distribution (most overused and most underused) may require attention. A heavily overused class is one in which the collection may not be strong enough to meet the needs of the users. Since most of the books are 
absent from the shelves, those few remaining are likely to be books of lesser value or interest (i.e., shelf bias is high). A heavily underused class needs the same kind of examination referred to earlier for the low turnover class. This type of collection use indicator was employed by McClellan (1956 before the library automation era. A modern example can be found in Dowlin and Magrath (1983).

A third way of comparing circulation and holdings data, and perhaps the most useful, is in terms of relative use (Jain, 1965). Relative use compares actual circulation with expected (in a probabilistic sense) circulation. For example, if class $\mathrm{x}$ accounts for $3 \%$ of the total collection, probability suggests that it should receive $3 \%$ of the total circulation. If it accounts for $7 \%$ of the circulation, it is heavily overused, If it accounts for $1 \%$ of the circulation, it is heavily underused. The difference between the expected circulation can be expressed in various ways, perhaps the most obvious being percentage of expected use (PEU). If a class has a PEU of 100 , it is behaving exactly as expected (e.g., it accounts for $0.5 \%$ of the use). A class with a PEU of 33 is heavily underused (use is exactly one third of the expected use). Lee and Lockway (1991) provide one good example of the use of this measure.

The three ways of relating collection data to circulation data (turnover rate, proportion of collection absent from the shelves, relative use) all do essentially the same thing: they allow the librarian to identify those subject classes (most overused, most underused) that seem to be most in need of attention. The data do not, in themselves, reveal what the corrective action needs to be (which requires some human interpretation) but they at least tell the librarian which classes to focus on.

The more data the librarian has that reflect use and demand for various subject areas, the better the collection development policy is likely to be. Interlibrary lending data can be useful when compared whit circulation data. For example, the fact that class $x$ is underused (as measured by circulation) but the library is borrowing many class $x$ books from other libraries to satisfy user requests, suggests that the wrong types of books are being bought in this class. Aguilar (1986) uses "ratio of borrowings to holdings" (RBH) as one indicator of classes that need corrective action. The RBH for a class is simply $\%$ of borrowings over $\%$ of holdings. Thus, a class which accounts for $15 \%$ of borrowings but only $8 \%$ of holdings gets an RBH of 1.9. The higher the RBH, the more likely it is that the library needs to buy more in this area. Aguilar combines RBH data with relative use circulation data to develop a purchasing model. Byrd et al. (1982)

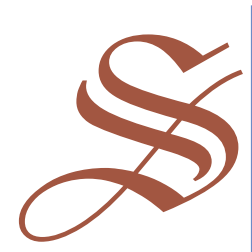

adopt a somewhat different approach, relating interlibrary loan data to current acquisitions data rather than to total holdings data. Their "collection balance indicator" again, can be used to identify classes that may need to be strengthened.

\section{In-house use}

Books and other materials can be used within the library instead of being borrowed, so circulation does not reflect total use. In a large research library, in-house use may gratly exceed circulation.

There are many ways of studying in-house use, from the very simple (recording materials left on tables or other study areas) to the complicated (interviewing samples of users within the library). Rubin (1986) describes and contrasts most of the possible approaches, and the problems of defining "use" in this context are discussed sin some detail in chapter 4 of Lancaster (1993). Daiute and Gorman (1974) describe rather elaborate procedures for the random sampling of users to be interviewed within the library.

Lancaster (1993) gives several examples of forms that can be used to record in-house use - e.g., stapled to the front of periodicals issues or slipped inside a bound volume.

The recording of materials used in the library, and left on tables or other reading areas, is greatly facilitated if bar codes are used to identify the books in the library. Such codes can then be ready by means of a scanner (wand). Use of technique is illustrated in papers by Lee and Lockway (1991) and by Titus et al. (1994).

The simplest of techniques for indicating which volumes have been used in the library, and which not, is the placing of an adhesive dot on the spine of a book before it is returned to the shelves after being collected from tables or other study areas. A complete description can be found in Slote (1989), who refers to it as the "spine marking" method.

\section{Evaluation of periodicals}

As budgets have shrunk, librarians have become increasingly concerned with the evaluation of the periodicals they subscribed to in order to decide which might be discontinued. Many possible evaluation criteria can be identified, from the purely subjective (opinions of faculty or other users) to the purely quantitative (number of uses a year). These various criteria are discussed in detail in Chapter 5 of Lancaster (1993). 


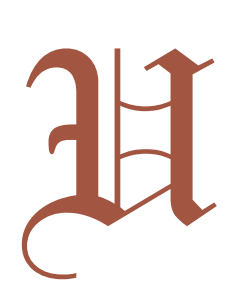

\author{
The most complete \\ discussion of weeding \\ methods and principles \\ appears in a book \\ by Slote (1989).
}

Ideally, one should be able to give a composite numerical score to each periodical in the library, based on the scores it achieves for all of the evaluation criteria selected. For example, a heavily used journal will achieve a high score for the "use" factor but a low score for the "cost" factor if it is very expensive. Broude (1978) illustrates the scoring of periodicals in this way, although his method is unnecessarily complicated because he takes into account too many evaluation factors and some of them are somewhat redundant. Lancaster (1993) suggests a much simpler scoring procedure.

The most important evaluation criteria are undoubtedly cost and use. When these are combined, the result is a measure of cost-effectiveness, namely cost and use. When these are combined, the result is a measure of cost-effectiveness, namely cost per use. Chrzastowsky (1991) gives and excellent example of the ranking of periodicals in an academic special library on the basis of cost per use.

Modern technologies (computer networks coupled with telefacsimile) make it increasingly feasible for a library to obtain photocopies from journals held by other libraries rapidly and economically. At the same time, commercial document delivery services now offer a convenient alternative to traditional library resource sharing. Consequently, librarians have become increasingly involved in cost-effectiveness analyses relating to the access versus ownership decision; that is, at what level of use within the library is it more economical to suscribe to a periodical rather than obtaining copies from elsewhere. Clearly, the breakeven point depends largely on the cost of the journal. Analyses of this type have been performed for many years, a classic being that of Williams et al. (1968). An excellent example of a recent study is that of Gossen and Irving (1995).

\section{Weeding of collections}

While true research libraries rarely dispose of any materials other than unwanted duplicate copies, most other libraries are well advised to weed their collections on a regular basis. Without weeding, the shelves of the library will be filled with obsolete materials or materials that have received little or no use since being added to the collection. Retaining these materials on open access shelves gives users the impression that the collection is not very useful or interesting and makes it more difficult for them to fin the better (e.g., more current) materials.

Furthermore, most libraries find themselves short of space. Space is wasted if the shelves are full of materials that are little if ever used. Even the large research libraries must be in- volved in one type of weeding: the retirement of less used materials to less accessible (and less costly) storage areas such as closed-access bookstacks or even off-site warehouses.

The most obvious criterion for weeding or retirement to storage is amount of use. Trueswell (1966) developed an ingenious method for retiring books to storage on the basis of the time elapsing between circulations. His method results in a general retirement rule (e.g., retire any book that has not circulated in the last 60 months]) and the effects of applying the rule can be rather precisely estimated (e.g., the books not circulating in the past 60 months constitute $40 \%$ of the entire collection; if retired to storage, they will be requested approximately $x$ times only in the next $y$ years). One example of the application of the principle can be found in Williams (1986).

Other librarians have attempted to develop general retirement rules based on criteria other than use, most obviously the age of the publication. The classic study in the research library environment is that of Fussler and Simon (1969), although this is now mainly of historical interest.

Just as periodicals can be given a numerical score to allow the optimization of cancellation decisions, books in a library could be given numerical scores to optimize weeding decision, where the score is the sum of several component scores (e.g., for age, amount of use, appearance on "recommended" lists, physical condition). Lancaster (1993) has illustrated how such a scoring method might be applied

The most complete discussion of weeding methods and principles appears in a book by Slote (1989).

In connection with weeding, it is important that librarians understand the phenomenaon of "obsolescence" since, in the library context, materials are considered to obsolesce as their use declines with age. The classic paper on obsolescence remains that of Line and Sandison (1974), although some of their assertions have since been repudiated —e.g., by Stinson and Lancaster (1987), Nakamoto (1988) and Sullivan et al. (1980-1981). The most complete discussion of obsolescence, presented from many different perspectives, can be found in an issue of Library Trends edited by Pao and Warner (1993).

\section{Space utilization}

This topic is closely related to that of weeding, as discussed in the previous section, Since the materials in a library, especially large one, may be kept at various levels of accessibility (open access shelves, closed access 
bookstacks, remote storage facilities), it is important that the degree of accessibility be related to the probable use. Most obviously the open access shelves of the library - the "prime" space- should be devoted to the materials most in demand.

A special space utilization situation is that related to bound periodicals. Given space to store say, 3000 volumes of bounds periodicals, the librarian must decide which titles should be held on these shelves for how far back. Clearly, a blanket decision -e.g., keep all titles five years back- is unlikely to result in good use of the space since some titles may still be in demand when ten or more years old, while others may rarely be used when more than two years old.

This is a true cost effectiveness decision, the measure being use per metre (or foot) of shelf space occupied. The principles involved in the decision are well covered in Groos (1969), Brookes (1970), Taylor (1976-1977), Wenger and Childress(1977), and Stayner and Richardson (1983).

\section{Materials availability studies}

Materials availability studies are performed to determine the probability that a book (or other item), known to be in the library's collection, is available to a user at the time he or she looks for it. There are two possible approaches:

1)Studies that require the cooperation of library users

2)Studies performed by means of simulations

In the first approach, a user is asked to complete a brief form to indicate which items he was looking for in the library and whether or not he was able to find them. During the period of the survey, forms can be handed out to all users entering the library. However, it is usually better to focus on a random sample of users and to do everything possible to get these people to cooperate.

Van House et al. $(1987,1990)$ give sample forms, together with detailed instructions on how to perform the survey. If properly conducted, a study of this kind can give a materials availability rate (the number of items found/the number of items looked for]), as well as allowing analyses to be performed to identify reasons for non-availability of materials (in circulation, in use in the library, at binding, misshelved, waiting to be reshelved, missing and so on).

The first studies of this kind were performed in British academic libraries (Urquhart and Schofield, 1971, 1972; Schofield et al., 1975) but many others have been conducted since then. A major analysis is that of Saracevic et al. (1977) and Mansbridge (1986) gives a useful review of earlier studies. A recent example can be found in Chaudry and Ashoor (1994).

Simulation studies try to achieve the same results — calculation of a materials availability rate plus analysis of reasons for nonavailability - without bothering library users. Suppose that one assembles, say, 500 bibliographic references representing items - books, reports, journal articles, and so on- that are fully representative of the kinds of materials that users of that library are likely to be looking for. An investigator walks into the library on a particular day with the list of references and checks to see how many not. In effect, the investigator is simulating 500 library users, each looking for a single item. As in the other procedure, a materials availability rate can be calculated (precisely) and reasons for nonavailability can be identified.

This is a very simple method to apply, the only essential requirement being that the list of references should represent the real needs and interests of library users. Possibilitites for arriving at such lists are discussed in Chapter 8 of Lancaster (1993).

The materials availability simulation was pioneered by Orr et al. (1968) for academic libraries and by DeProspo et al. (1973) for public libraries.

The major factors affecting the probability that a book will be on the shelf and available when looked for are (1) its popularity, (2) the number of copies owned, and (3) the length of the loan period. Having these data for the books in a library allows one to calculate rather accurately the probability of availability of any item. "Popularity" needs not to be a nebulous factor; it can be quantified precisely (e.g., in terms of frequency with which a book has been borrowed or simply the date on which it was last borrowed). Buckland (1975) provides a detailed account of these availability factors and how they interact.

\section{REFERENCE SERVICES EVALUATION}

The major functions of a reference service are the answering of factual-type questions and the performance of database searches. Some reference departments also have responsibilities in the area of bibliographic instruction.

\section{Question-answering}

Evaluative activities related to question-answering range from the simple to the complex.

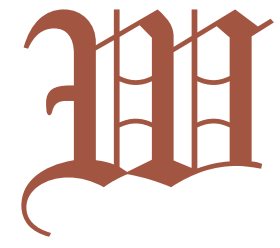

This is a very simple method to apply, the only essential requirement being that the list of references should represent the real needs and interests of library users 
The simplest activity is the recording, by members of the reference staff, of questions received and action taken, including sources used and whether the librarian felt confident that the question was dealt with satisfactorily. Hawley (1970) gives a good example of a form used for such purpose. A slightly more sophisticated approach, described by Murfin and Gugelchuk (1987), involves two forms for each question, one completed by the reference librarian and one by the user, thus allowing a comparison to be made of the views of each on the success of the transaction. Clearly, this two faceted approach could not be applied for questions arriving by telephone.

The most sophisticated approach to this aspect of evaluation involves the use of a set of questions for which complete and correct answers have been established in advance. The set can be used to test whether the reference librarians in a particular library are able to supply complete and correct answers or not. The questions can be applied obstrusively or unobstrusively.

In an obstrusive study, the librarians know they are being tested. Usually they operate under time constraints - i.e., they are to answer as many questions as possible within a particular period, say four hours. Pizer and Cain (1968) may have been the first to describe obstrusive reference studies of this type.

In the unobstrusive version, the librarians do not know they are being evaluated. Questions are posed by "volunteers" (e.g., university students) acting as though they are real library users with real questions. In most studies, the questions are posed by telephone; in a few they are made by personal visit. The reference department is judged by the proportion of the questions that they are able to answer completely and correctly.

Crowley and Childers (1971) popularized this approach, Childers (1972) discusses the implementation problems, and Crowley (1985) contributes a useful review. The largest study of this type in a single academic library has been described by Lancaster et al. (1991a).

\section{Database searching}

This section of the review deals with the evaluation of subject searches. In this connection, the term database refers to any bibliographic source in which subject searches can be performed, including databases available through remote online access, CD-ROMs, library catalogs, and printed indexing/abstracting publications.

When a library user performs a search (or when a librarian performs the search for a user) he or she is looking for materials that will satisfy, or help to satisfy, some information need. In most cases, the searcher would like to find a few items, preferably of high quality, that deal with the subject of interest. Less often, a really comprehensive search is wanted -the searcher would like to find everything available on the subject. In a few rare cases, a single item on the topic will be enough.

The results of a subject search can be evaluated in a purely subjective way -is the user satisfied or not? In general, however, it is better to make the evaluation more quantitive: how many of the items retrieved are useful to the user, how many are really important, how many are new to the user? Such results can be expressed as performance ratios: a precision ratio (number of useful items retrieved/total items retrieved), major precision ratio (number of really important items/total items retrieved), and a novelty ratio (numbers of new and useful items/number of useful items retrieved).

To get feedback on the results of a subject search will usually mean that the user (requester) must complete a brief evaluation questionnaire. Examples of such questionnaires can be found on chapter 11 of Lancaster (1993).

However, an evaluation based only on the items retrieved in a search gives an incomplete picture of its success. In almost cases, there will be other items in the database, items not retrieved, that would be judged useful if the user saw them. In some cases, these might be more important than some of the other useful items that were retrieved; they may even be more important than all of the items that were retrieved. For example, they could be items important to the user's research but not previously known to him.

It follows, then, that a complete evaluation of a subject search must make attempt to determine, or at least estimate, how many useful items have been missed. If this were known, it would be possible to apply a further performance ratio to the results - a recall ratio (number of useful items retrieved/number of useful items in the database). Unfortunately, it is not at all easy to estimate how many useful items were missed in a search. Although several estimation procedures exist (see Lancaster and Warner, 1993), they are somewhat difficult to apply. A library would not want to attempt some estimate on a routine basis, although it would be important to do so for a sample of searches if the library was really serious about the evaluation of a database searching service (e.g., an SDI service within an industrial organization).

The most complete evaluation of a database searching service remains that of Lancaster

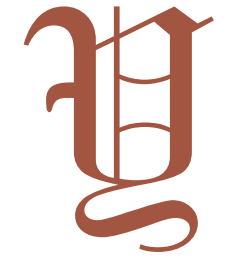

\author{
The most sophisticated approach \\ to this aspect of evaluation \\ involves the use of a set of \\ questions for which complete and \\ correct answers have been \\ established in advance.
}


(1968). Saracevic et al. (1998) present the results of an important research project that among other things, showed that different searchers (even highly experienced ones) will use completely different approaches to search on a particular topic and will tend to retrieve different items. McCue (1988) describes a rare unobstrusive study of database searching: the same searches were performed by different libraries without their knowing they were being evaluated. Lancaster et al. described a study of subject searchers in a very large OPAC, using very stringent criteria (did the searcher find "the best" items on the subject?).

Clearly, the most difficult searches to evaluate are those performed by library users themselves since it is very difficult to collect data form users under these circumstances. For an example of a detailed evaluation of user searches in a CD-ROM database see Lancaster et al. (1994).

\section{Bibliographic instruction}

\section{The evaluation of bibliographic instructions is quite different form other facets of library-related evaluation because the metodologies come more from the field of education than from library science}

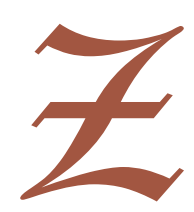

Bibliographic instruction - teaching people how to use the resources of the library or information resources in general- is an activity that has become of increasing importance in the last few years, especially in academic libraries, and the activity is one that may reside in the reference department. One reason why bibliographic instruction has gained prominence is the fact that the library has increasingly become a self-service institution with users themselves doing more and more of the things formerly done by librarians.

The evaluation of bibliographic instructions is quite different form other facets of library-related evaluation because the metodologies come more from the field of education than from library science. The most complete discussion can be found in Chapter 12 of Lancaster (1993), which deals with the following aspects: reaction of instructors, reaction of those who are being instructed, use of independent observers, evaluation of learning, behavioral changes in those instructed, evaluation of program results, and cost-effectiveness aspects.

\section{COST-EFFECTIVENESS AND COST-BENEFIT STUDIES}

Several cost-effectiveness studies relating to various aspects of library service have been mentioned throughout this review. The following section will deal with cost-effectiveness analyses as a "genre" of library evaluation studies.

Clearly, a prerequisite for a cost-effectiveness study is the calculation of the cost of some library service. The costing of library services is fully dealt with in Mitchell et al. (1978), Griffiths and King (1983), Citron and Dodd (1984), Roberts (1984, 1985), Rosenberg (1985) and Kantor (1989). A simplified approach is given in Chapter 14of Lancaster (1993).

\section{Cost-effectiveness analyses}

Cost-effectiveness are studies that relate to return on investment Most often, studies of this type are performed to compare different approaches to achieving particular results or to determine the optimum allocation of resources available for some purpose (e.g., the optimum allocation of funds available for providing periodical access for library users).

Cost-effectiveness measures relate the cost of a service to some measure of its effectiveness. Frequently, the measure of effectiveness is simple "use". Cost per circulation, cost per use of a periodical, cost per question answered, and cost per search performed could all be used as cost-effectiveness measures, although more refined measures (e.g., cost per useful item retrieved and cost per questions answered completely and correctly) are to be preferred.

One type of cost-effectiveness study is performed to determine which periodicals should be discontinued because they have high cost-per-use figures associated with them. A good example can be found in Chrzastowski (1991). Closely related are studies that compare he cost of owning a periodical with the cost of obtaining copies (from other libraries or from commercial suppliers) when the need arises. A recent example can be found in Gossen and Irving (1995).

Cost-effectiveness analyses relating to the optimum use of space can be found in Gross (1969), Brookes (1970), Taylor (1976-1977), Wenger and Childress (1977), and Stayner and Richardson (1983).

Analyses that have become increasingly important in recent years are those that look at cost effectiveness aspects of making information sources available in different formats: print versus CD-ROM, CD-ROM versus online access, and so on. Excellent comparison of CD-ROM versus online access, and so on. Excellent comparisons of CD-ROM versus online remote access versus loading the database onto the institution's own computer can be found in the work of Meyer $(1990,1993)$. The same situation is deal with by Halperin and Renfro (1988), and Machovec and Brunning (1991) have identified the various factors that need to be considered in making decisions of his type. CD-ROM versus online access are dealt with variously by Welsh (1989), Huang and McHa- 
le (1990) and Huang (1991), although these studies are of variable quality (see Lancaster -1993-, Chapter 14, for a critique).

Cost effectiveness analyses have to do with the optimum allocation of resources. In this regard, it is important to recognize the phenomenon of the "90\% library" (Bourne, 1965). In essence, this means that, for any particular service, it will be possible to satisfy some specified proportion of the total demands $(85 \%$ or $90 \%$ perhaps) efficiently and economically. To get much beyond this point, however, would require a completely disproportionate level of expenditure. For example, perhaps $90 \%$ of access needs can be satisfied by subscribing to 100 journals at a total cost of around $\$ 5000$. To satisfy $95 \%$ of the needs, however, 250 journals may be needed and the cost increases to around $\$ 12,000$. Other examples of diminishing returns in library services can be found in Chapter 14 of Lancaster (1993).

\section{Cost-benefit studies}

A cost benefit study looks at the relationship between the cost of some activity and the benefits of arising from it. Ideally, both sides of the cost benefit equation shoud be ePUWAERRENCES

in the same unit - a monetary one. Herein lies the problem of performing cost-benefit stu-

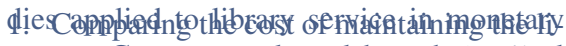

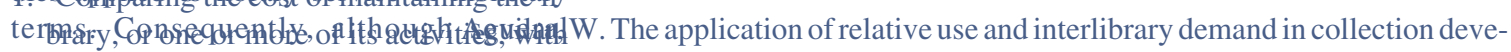

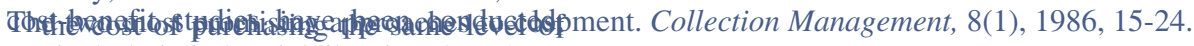

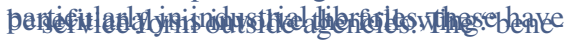

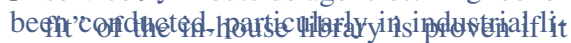

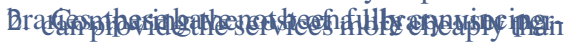

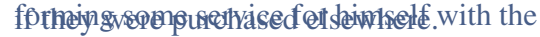
cost of the librarian providing the service to him. This type of analysis, which has been applied most often to database sear-

the cost of user time and the cost of librarian time.

An example of the first of these approaches can be found in the work of Magson (1973). Examples of the second can be found in Rosenberg (1969), Kramer (1971), Mason (1972), Nightingale (1973), Bleck (1977), Collete and Price (1977), Johnson et al. (1977) Jensen et al. (1980) and Estabrook (1986).

A more sophisticated approach can be found in the studies of king research Inc. (1982, 1984), including Roderer et al. (1983), and Griffiths and King (1991). Basically, their approach compares the cost of an information service with the financial benefit associated with such things as savings of time and avoidance of duplication in research.

\section{OTHER ASPECTS}

\section{Range and scope services}

Libraries can be compared on the basis of the depth and breadth of the services they provide. Evaluations of this kind were pioneered by Orr et al. (1968), who developed a questionnaire to be completed by library directors. The questionnaire addressed such matters as hours of opening, services provided, lending and other policies and facility availability. They were able to assign numerical scores to the various service elements, allowing libraries to be compared on the basis of overall score and /or component scores relating to different facets of service (document delivery, reference and so on).

This and other similar studies are reviewed in Baker and Lancaster (1991).

\section{Resource sharing}

Resource sharing activities may be the least evaluated aspect of library services, although Peat, Marwick, Mitchell \& Co. (1975) have identified the relevant evaluation criteria for various aspects of resource sharing.

There have been countless studies of fill rate and delivery times for interlibrary lending, dealing both with groups of libraries in a particular region (e.g., Medina, 1988) and individual libraries (Horton, 1989).
More sophisticated analyses of resources sharing activities usually take the form of cost-effectiveness studies. For example, Lowry (1990) looks at interlibrary loan from the lending institution's point of a view as a loss of investment, and Bonk and Pilling (1990) give cost data for the various component activities associated with borrowing and with lending. Related cost effectiveness analyses can be found in the work of Kavanagh (1988), Rutledge and Swindler (1988) and MacDougall et al. (1990).

\section{Surveys of user satisfaction}

This survey has concentrated largely on studies designed to gather objective data on the performance of library services. Nevertheless, the subjective impressions of users regarding the library's services do have value. They indicate how "happy" the customers are and also can be used in a diagnostic way to identify possible sources of dissatisfaction or types of users who are less satisfied than others. Questionnaires can be employed with samples of library users to determine their satisfaction with the library's services in general or their satisfaction with the services provided on a particular visit.

Samples of questionnaires can be found in Van House et al. $(1987,1990)$ and Sumsion (1993), among other sources. A good recent example of a survey in an academic library is Mccarthy (1995). Her study was able to identify sources of both satisfaction and dissatisfaction and to relate degree of satisfaction to type of student user. 
Baker, S. L. and Lancaster, F.W. The Measurement and Evaluation of Library Services, Second edition. Arlington, V.A. Information Resources Press, 1991.

Blick, A. R. The value of measurement in decision-making in an Information Unit —a cost benefit analysis. Aslib Proceedings, 29, 1977, 189-196.

Bonk, S. C. and Pilling, D. Modelling the economics of Interlending. Interlending and Document Supply, 18, 1990, 52-56.

Bourne, C. P. Some user requirements stated quantitatively in terms of the $90 \%$ library. In: Electronic Information Handling, ed. by A. Kent et al. pp. 93-110. Washington, DC, Spartan Books, 1965.

Brookes, B. C. Obsolescence of special library periodicals: sampling errors and utility contours. Journal of the American Society for Information Science, 21, 1970, 320-329.

Broude, J. Journal deselection in an academic environment: a comparison of faculty and librarian choices. Serials librarian, 3, 1978, 147-166.

Buckland, M. K. Book Availability and the Library User. New York, Pergamon, Press, 1975.

Byrd, G.D. et al. Collection development using interlibrary loan borrowing and acquisitions statistics. Bulletin of the Medical Library Association. 70, 1982, 1-9.

Chaudry, A. S. and Ashoor, S. Comprehensive materials availability studies in academic libraries. Journal of Academic Librarianship, 20, 1994, 300-305.

Childers, T. Managing the quality of reference/information service. Library Quarterly, 42, 1972, 212-217.

Chrzastowski, T. E. Journal collection cost-effectiveness in an academic chemistry library: results of a cost/use survey at the University of Illinois at Urbana-Champaign. Collection Management, 14 (1/2), 1991, 85-98.

Citron, H. R. and Dood, J. B. Cost allocation and cost recovery considerations in a special academic library: Georgia Institute of Technology. Science and Technologies Libraries, 5 (2), 1984, 1-14.

Coale, R. P. Evaluation of a research library collection- Latin America Colonial history at the Newberry. Library Quarterly, 35, 1965, 173-184.

Collete, A. D. and Price, J. A. A cost/benefit evaluation of online interactive bibliographic searching in research and engineering organization. In The value of information: Collection of Papers Presented at the 6th Mid-Year Meeting [of ASIS], May 19-21. 1977, pp. 24-34. Syracuse, NY, Syracuse University, 1977.

Crowley, T. and Childers, T. Information Service in Public Libraries: Two Studies. Metuchen, NJ, Scarecrow Press, 1971.

Daiute, R. J. and Gorman, K. A. Library Operations Research. Dobbs Ferry; NY, Oceana Publication, 1974.

DeProspo, E. R. et al. Performance Measures for public Libraries. Chicago, Public Library Association, 1973.

Dowlin, K. and Magrath, L. Beyond the numbers - a decision support system. In: $\mathrm{Li}_{-}$ brary Automation as a Source of Management Information; ed. by F.W. Lancaster, pp.27-58. Urbana, University of Illinois, Graduate School of Library and Information Science., 1983.

Estabrook, L. S. Valuing a document delivery system. $R Q, 26,1986,58-62$. 
Fussler, H.H. and Simon, J.L. Patterns in the Use of Books in Large Research libraries. Chicago, University of Chicago Press, 1969.

Gossen, E.A. and Irving, S. Ownership versus access and low use periodical titles. $\mathrm{Li}$ brary Resources \& Technical Services, 39, 1995, 43-52.

Griffiths, J.M. and King, D.W. Library Cost Benefit Analysis: A Manual Prepared for the library Cost Benefit Analysis Seminar Presented at the SUNY/OCLC Network Annual Directors Day on February 17, 1983. Rockville, MD, King Research, Inc., 1983.

Griffiths, J.M. and King, D.W. A Manual on the Evaluation of Information Centers and Services. Neuilly-sur-Seine, North Atlantic Treaty Organization, Advisory group for Aerospace Research and development, 1991. AGARD-AG-310.

Gross, O.V. Citation Characteristics of astronomical literature. Journal of Documentation, 25, 1969, 344-347.

Halperin, M. and Renfro, P. Online vs Cd-ROM vs. Onsite: high volume searching-considering the alternatives. Online 12 (6), 1988, 36-42.

Hawley, M. B. Reference statistics. $R Q, 10,1970,143-147$.

Horton, W., Jr. Interlibrary loan turnaround times in science and engineering. Special Libraries 80, 1989, 245-250.

Huang, S.T. CD-ROM database searching vs traditional online database searching. Proceedings of the National Online Meeting 1991; ed. by M.E. Williams, pp. 139-148. Medford, N.J. Learned Information, 1990.

Huang St. and McHale, T. J. A cost effectiveness comparison between print and online versions of the same frequently-used sources of business and financial information. Proceedings of the National Online Meeting 1990; ed. by M.E. Williams, pp. 161-168. Medford N.J., Learned Information 1990.

Jain, A.K. A Sampled Data Study of Book Usage in the Purdue University Libraries. Lafayette, IN, Purdue University, 1965.

Jensen, R. J. et al. Costs and benefits to industry of online literature searches. Special Libraries, 71, 1980, 291-299.

Johnson, F. D. et al. NASA Tech Brief Program: Cost Benefit Evaluation. Denver, University of Denver Research Institute, 1977.

Kantor, P. B. Library cost analysis. Library Trends, 38, 1989, 171-188.

Kavanagh, R. TRESNET: The Trent Resource Sharing Network. Canadian Library Journal, 45, 1988, 283-288.

King Research Inc. A study of the Value of information and the Effect on the Value of Intermediary Organizations, Timelines of Services and Products, and Comprehensiveness of the EDB. Rockville, MD, King Research, Inc., 1984. DOE/NMB-1078- DE 85003670.

King Research Inc. Value of the Energy Data Base. Rockville, MD, 1982.

Kountz, J. What's in a library: comparing holdings to the constituencies served. $\mathrm{Li}$ brary Hi-Tech, 9(2), 1991, 31-48, 61.

Kramer, J. How to survive in industry: cost justifying library services. Special Libraries, 62, 1971, 487-489.

Lancaster, F. W. Evaluation of the MEDLARS Demand Search Service. Bethesda, MD, National Library of Medicine, 1968. 
Lancaster, F. W. If you Want to Evaluate your Library... Second edition. Champaign-Urbana University of Illinois, Graduate School of Library and Information Science.

Lancaster, F. W. and Warner, A. Information Retrieval Today /third edition of Information Retrieval Systems: Characteristics, Testing and Evaluation). Arlington, VA, Information Resources Press, 1993.

Lancaster, F. W. et al. The diagnostic evaluation of reference service in an academia library. In: Evaluation of Public Services and Public Services Personnel: Proceedings of the Thirty-second Allerton Park Institute; ed. by Allen, pp. 43-57. Urbana, University of Illinois, Graduate School of Library and Information Science, 1991a.

Lancaster, F. W. et al. Identifying barriers to effective subject access in library catalogs. Library Resources \& Technical Services, 35, 1991b, 377-391.

Lancaster, F. W. et al. The relationship between literature scatter and journal accesibility in an academia special library. Collection Building, 11(1), 1991c, 19-22.

Lancaster, F. W. et al. Searching databases on CD-ROM: comparison of the results of end-user searching with results from two modes of searching by skilled intermediares. $R Q, 33,1994,370-386$.

Lee, D. C. and Lockway, L. A. Using an online comprehensive library management system in collection development. Collection Management, 14(3/4), 1991, $61-73$.

Line, M. B. and Sandison, A. "Obsolescence" and changes in the use of literature with time. Journal of Documentation, 30-1974, 283-350.

Lopez, M. D. The Lopez citation technique of in depth collection evaluation explicated. College \& Research library, 44, 1983, 251-255.

Lowry, C. B. Resource sharing or cost shifting? The unequal burden of cooperative cataloging and ILL in network. College and Research Libraries, 51, 1990, $11-19$.

MacDougall, A. F. et al. Effectiveness of a local inter-loan system for five academic libraries: an operational research approach. Journal of Documentation, 46, 1990, 353-358.

Machovec, G.S. and Brunning, D. R. Choices: collection management issues of the IOLS. Integrated Online Library Systems (Proceedings), 1991, 83-91.

Magson, M.S. Techniques for the measurement of cost-benefit in information centres. ASLIB Proceedings, 25, 1973, 164-185.

Mansbridge, J. Availability studies in libraries. Library and Information Science Research, 8, 1986, 299-314.

Mason, D. PPBS: application to an industrial information and library service. Journal of Librarianship, 4, 1972, 91-105.

McCarthy, C.A. Students' perceived effectiveness using the university library. College and Research Libraries, 56, 1995, 221-234.

McClellan, A. W. New concepts of service, Library Association Record. 58, 1956, 299-305.

McCue, J. H. Online Searching in Public Libraries: a Comparative Study of Performance. Metuchen, N. J., Scarecrow Press, 1988.

Medina, S. O. Network of Alabama Academic Libraries interlibrary loan turnaround time survey. Southeastern Librarian, 38, 1988, 105-107. 
Meyer, R.W. Management, cost, and behavioral issues with locally mounted databases. Information Technology and Libraries, 9, 1990, 226-241.

Mitchell B. J. et al. Cost Analysis of Library Functions; a Total System Approach. Greenwich, CT, JAI Press Inc., 1978.

Murfin, M.E. and Gugelchuk, G.M. Development and testing on a reference transaction assessment instrument. College \& Research Libraries, 48, 1987, 314-338.

Nakamoto, H, Synchronous and diachronous citation distributions. In: Informetrics 88; ed. by L. Egghe and R. Rousseau, pp. 157-163, Amsterdam, Elsevier, 1988.

Nightingale, R.A. A cost-benefit study of a manually-produced current awareness bulletin. Aslib Proceedings, 25, 1973, 153-157.

Nisonger, T.E. Collection Evaluation in Academic Libraries; A Literature Guide and Annotated Bibliography. Engelwood, CO, Libraries Unlimited, 1992.

Orr, R. H, Measuring the goodness of library services: a general framework for considering quantitative measures. Journal of Documentation, 29, 1973, 315-332.

Orr, R. H, et al. Development of methodologic tools for planning and managing library services. Bulletin of the medical Library Association, 56, 1968, 235-403.

Pao, M. L and Warner, AJ., eds. The Depreciation of Knowledge, Library Trends, 41(4), Spirng, 1993 (complete issue).

Peat, Marwick, Mitchell \& Co. California Public Library Systems: a Comprehensive Review with Guidelines for the Next Decade. Los Angeles, 1975.

Pizer, I. H., and Cain, A. M. Objective tests of library performance. Special Libraries, 59, 1968, 704-711.

Roberts, S. A., ed. Costing and the Economics of Library and Information Services. London, Butterworths, 1985.

Roderer, N. K. et al. The Use and Value of Defense Technical Information Center Products and Services, Rockville, MD. King Research Inc., 1983. AD-A 130805/5.

Rosenberg, K. C. Evaluation of an industrial library: a simple minded technique. Special Libraries, 60, 1969, 635-638.

Rosenberg, P. Cost Finding for Public Libraries. Chicago, American Library Association, 1985.

Rubin, R. Inhouse Use of Material in Public Libraries. Urbana, University of Illinois, Graduate School of Library and Information Science.

Rutledge, J. and Swindler, L. Evaluating membership in a resource-sharing program: the Center for Research Libraries. College \& Research Libraries, 49, 1988, 409-424.

Saracevic, T. et al. Causes and dynamics of user frustration in an academic library. College \& Research Libraries, 38, 1977, 7-18.

Saracevic, T. et al. Study of information seeking and retrieving. Journal of the American Society for Information Science, 39, 1988, 161-216.

Schofield, J. L. et al. Evaluation of an academic library's stock effectiveness. Journal of Librarianship, 7, 1995, 207-227.

Slote, S. J. Weeding Library Collections. Third edition. Littleton, CO, Libraries Unlimited, 1989. 
Stayner, R. A. and Richardson, V.E. The Cost effectiveness of Alternative Library Storage Programs. Clayton, Victoria, Monash University, Graduate School of Librarianship, 1983.

Stinson, E. R. and Lancaster, F. W. Synchoronous versus diachronous methods in the measurements of obsolescence by citation studies. Journal of Information Science, 13, 1987, 65-74

Sullivan, M.V. et al. Obsolescence in biomedical journals: not an artifact of literature growth. Library Research, 2, 1980-1981, 29-45.

Sumsion, J. Practical Performance Indicators - 1992. Loughborough, Loughborough University of Technology, 1993.

Taylor, C. R. A practical solution to weeding university library periodicals collections. Collections Management, 1(3/4), 1976-1977, $27-45$.

Titus, E. M. Barcoding as a tool for collection use analysis: a pilot project. Information Technology and Libraries, 13, 1994, 257-265.

Trueswell, R. W. Determining the optimal number for volumes for a library's core collection. Libri, 16, 1966, 49-60.

Urquhart, J. A. and Schofield, J.L. Measuring reader's failure at the shelf. Journal of Documentation, 27, 1971, 272-286.

Urquhart, J. A. and Schofield, J.L. Measuring reader's failure at the shelf in three university libraries, Journal of Documentation, 28, 1972, 233-241.

Van House, N. A. et al. Measuring Academic Library Performance: a Practical Approach. Chicago, American Library Association, 1990

Van House, N. A. et al. Output Measures for Public Libraries: a Manual of Standardized Procedures. Second edition. Chicago, American Library Association, 1987.

Welsh, J. J. Evaluation of CD-ROM use in a government research library. Laserdisk Professional, 2(6), 1989, 55-61.

Wenger, C. B. and Childress, J. Journal Evaluation in a large research library. Journal of the American Society of Information Science, 28, 1977, 293-299.

White, M. D. and Abels, E.G. Measuring service quality in special libraries: lessons from service marketing. Special Libraries, 86, 1995, 36-45.

Williams, R. Weeding an academic lending library using the Slote method. British Journal of Academic Librarianship, 1, 1986, 147-159. 